\title{
Determination of Physical Problems for Adult Patients with Asthma
}

\author{
Dr. Hussein Hadi Atiyah*
}

\begin{abstract}
Background: Asthma is considered as a major public health problem in many countries. It is one of the most common chronic disease affecting both adults and children. According to world health organization there are at least 300 million people suffer from asthma worldwide and more than 180,000 people die from it each year. Therefore, the study aims to determine physical problems for adult patients with asthma and to find out the relationship between physical problems with demographic characteristics.

Materials and methods: - A descriptive study was carried out in Baghdad teaching hospital and AlYarmook teaching hospital for the period of $1 \backslash 12 \backslash 2011$ to $2 \backslash 5 \backslash 2012$. A purposive (non probability) sample of (50) patients. Questionnaire was constructed for the purpose of the study. Data were collected through the application of the questionnaire and interview technique. Data were analyzed through descriptive statistical approach (frequency and percentage) and inferential statistical approach (Pearson correlation and mean of score) by using of SPSS 16.0.

Results: The study results indicated that the range of age was between (40-49) year and most of them were male, married and employed in government officer, read and write they live in rural, barely sufficient of monthly income. There is high physical problems such as cough, wheezing, dyspnea, tachycardia and weight loss.

Conclusions:- There is no relationship between physical problems with marital status educational level. There is moderate relationship between the remaining variables this mean that physical problems are present with all variables.

Recommendation:-The study recommended that educational programs should be constructed or designed for patients toward health care awareness for patients with asthma. Patients with asthma should undergo tests to identify the substances that precipitate the physical problems. Patients are instructed to avoid the causative agents wherever possible.
\end{abstract}

Keywords:- physical problems, asthma

\section{INTRODUCTION}

Asthma was first recognized in ancient Egypt and treatment was inhalation of frankincense. Officially recognized as a specific respiratory problem separate from others was first recognized and named by Hippocrates Circa 450 BC (Zuskin et al., 2008).Asthma is a chronic lung condition with ongoing airway inflammation that results in recurring acute episodes (attacks) of breathing problems such as coughing, wheezing, chest tightness, and shortness of breath. These symptoms occur because the inflammation makes the airways overreact to a variety of stimuli including physical activity, upper respiratory infections, allergens, and irritants. Exposure to these stimuli--often called triggers--creates more swelling and blocking of the airways. Asthma episodes can be mild, moderate, or even lifethreatening. Vigorous exercise will cause symptoms for most students with asthma if their asthma is not well-controlled. Some students experience symptoms only when they exercise. However, today's treatments can successfully control asthma so that students can participate fully in physical activities most of the time (Linton, 2007). Asthma is a disease that affects the breathing passages of the lungs (bronchioles). Asthma is caused by chronic (ongoing, long-term) inflammation of these passages. This makes the breathing passages, or airways, of the person with asthma highly sensitive to various "trigger when the inflammation is "triggered" by any number of external and internal factors, the passages swell and fill with mucus. Muscles within the breathing passages contract (bronchospasm), causing even further narrowing of the airways. This narrowing makes it difficult for air to be breathed out (exhaled) from the lungs. This resistance to exhaling leads to the typical symptoms of an asthma attack. Because asthma causes resistance, or obstruction, to exhaled air, it is called an obstructive lung disease.

* Assist. Prof. / College of Nursing / University of Baghdad / hhatia_1960@yahoo.com 
The medical term for such lung conditions is chronic obstructive pulmonary disease or COPD. COPD is actually a group of diseases that includes not only asthma but also chronic bronchitis and emphysema (Jenkins et al., 2004; Smeltzer et al., 2008). Asthma is a disease of the lungs in which affected persons have trouble breathing, may feel tightness in the chest and may wheeze and/or cough. According to the Centers for Disease Control and Prevention (CDC), asthma currently affects 7.3 percent of adults and 9.4 percent of children. Furthermore, problems with asthma resulted in 10.6 million visits to the doctor in 2006. Thus, asthma is a severe public health problem that affects a significant portion of the population. Three major physical characteristics are associated with asthma, and people with the disease can manifest one, two or all three of them (Nemery et al., 2002; Basavanthappa, 2009). In most people with asthma, the difficulty breathing happens periodically. When it does happen, it is known as an asthma flare-up also known as an asthma attack, flare, episode, or exacerbation (Pasternack et al., 2005; Lewis et al., 2004). Asthma as a result of (or worsened by) workplace exposures is a commonly reported occupational respiratory disease. Still most cases of occupational asthma are not reported or are not recognized as such. Estimates by the American Thoracic Society (2004) suggest that $15-23 \%$ of new-onset asthma cases in adults are work related (Boulet, 2009). In one study monitoring workplace asthma by occupation, the highest percentage of cases occurred among operators, fabricators, and laborers (32.9\%), followed by managerial and professional specialists $(20.2 \%)$, and in technical, sales, and administrative support jobs (19.2\%). Most cases were associated with the manufacturing (41.4\%) and services $(34.2 \%)$ industries (Harrington and Lee-Chiong, 2007; Lewis et al., 2007). Asthma is caused by environmental and genetic factors (Burrows et al., 1989). These factors influence how severe asthma is and how well it responds to medication (Simpson et al., 2001). Maternal tobacco smoking during pregnancy and after delivery is associated with a greater risk of asthmalike symptoms, wheezing, and respiratory infections during childhood (Beuther, 2010). Low air quality, from traffic pollution or high ozone levels, has been repeatedly associated with increased asthma morbidity and has a suggested association with asthma development that needs further research (Celedon et al., 2002; Holguin and Fitzpatrick, 2010; WHO, 2009).

Asthma is considered as a major public health problem in many countries. It is one of the most common chronic disease affecting both adults and children. According to world health organization there are at least 300 million people suffer from asthma worldwide and more than 180,000 people die from it each year. Despite the availability increasing treatment, asthma-related morbidity and mortality continues to rise. The prevalence of asthma is increasing in developed as well developing countries through the world. The current prevalence of asthma is estimated to be 5 to more than $10 \%$ (Maddox and Schwartz, 2002).

Asthma affects people of all ages, but it most often starts during childhood. In the United States, more than 22 million people are known to have asthma. Nearly6 million of these people are children. The prevalence of asthma has increased significantly since the 1970s. As of 2010, 300 million people were affected worldwide (Smeltzer et al., 2010; Self et al., 2009). In 2009 asthma caused 250,000 deaths globally (Moore et al., 2010). Despite this, with proper control of asthma with step down therapy, prognosis is generally good (Delacourt, 2004).

\section{MATERIAL AND METHODS}

A descriptive analytic study was carried out throughout the present study to determine the physical problems who attended the inpatient in teaching hospital in Baghdad city. The study was carried out during the period extended from the $1^{\text {st }}$ December 2011 to $2^{\text {nd }}$ May 2012. In order to obtain valid and comprehensive data, the study was conducted inpatient. The following was included Baghdad teaching hospital and Al-Yarmokt teaching hospital. In order to obtain accurate data and representative sample, a non probability (purposive) sample was selected. The sample consisted of (50) patients. These patients were attending inpatients in teaching hospital in Baghdad city. The sample was selected according to the following criteria: adult patients 20 years old and above, patients with asthma, patients free from mental disorders, patients agreed to participate in the study, and free from systemic disease. A questionnaire- interview format was designed and developed by the researchers for the purpose of the study; such development was employed through the available literatures, clinical background and interview with patients who has asthma. All the items were measured on scale of (3) indicates that the problems were persistent as (always) and (2) Indicates presence of the problems as (sometimes) and (1) indicates the absence of the problems as (never). Rating scale was used to rate the frequency and extension of the problems. The questionnaire consisted of part one which deals with demographic characteristics. It consisted of 
(7) items included age, gender, marital status, level of education, occupation, monthly income, and residential area. While the second part deals with physical problems aspects. They were designed for the purpose of the patient's physical problems and they consisted of (21) items. The content validity of the instrument was established through a panel of (10) experts. The years of experience with mean of (19.5) years, and $(\mathrm{SD}=7.43)$. They were asked to determine the content validity and investigate the clarify adequacy of the study questionnaire. The experts' responses were evaluated based on their agreements or disagreements on each item and its measurement. The result had indicated that all the experts agreed upon the items relevancy to the whole instrument except some of the items who suggested rewarding of statements. Opinions and suggestions of experts were taken in consideration and changes were done at the final draft of the questionnaire. The data were collected by using the questionnaire structured format through interview technique. Each patient was interviewed personally by the researchers. Throughout each interview explanation of the study was held up with patient in order to accept participation. Each interview took approximately from (15-25) minutes. Data were collected between 8.30 am to $1.30 \mathrm{pm}$. The determination was conducted during the period of the $2^{\text {nd }}$ January 2012 to $15^{\text {th }}$ February 2012. The data were analyzed through the use of Statistical Package of Social Sciences (SPSS) version 16.0.

\section{RESULTS}

Table (1): Distribution of adult patients (study sample) by their demographic characteristics.

\begin{tabular}{|c|c|c|c|}
\hline$\overline{\text { Age ( years ) }}$ & Frequency & Percent & Cumulative Percent \\
\hline $20-29$ & 5 & 10.0 & 10.0 \\
\hline $30-39$ & 18 & 36.0 & 46.0 \\
\hline $40-49$ & 23 & 46.0 & 92.0 \\
\hline$\leq 50$ & 4 & 8.0 & 100.0 \\
\hline Total & 50 & 100.0 & \\
\hline Gender & Frequency & Percent & Cumulative Percent \\
\hline Male & 36 & 72.0 & 72.0 \\
\hline Female & 14 & 28.0 & 100.0 \\
\hline Total & 50 & 100.0 & \\
\hline Marital status & Frequency & Percent & Cumulative Percent \\
\hline Married & 36 & 72.0 & 72.0 \\
\hline Single & 14 & 28.0 & 100.0 \\
\hline Total & 50 & 100.0 & \\
\hline Level of education & Frequency & Percent & Cumulative Percent \\
\hline No read and write & 5 & 10.0 & 10.0 \\
\hline Read and write & 23 & 46.0 & 56.0 \\
\hline Intermediate school & 4 & 8.0 & 64.0 \\
\hline Secondary school & 8 & 16.0 & 80.0 \\
\hline Institute & 5 & 10.0 & 90.0 \\
\hline College and above & 5 & 10.0 & 100.0 \\
\hline Total & 50 & 100.0 & \\
\hline Occupation & Frequency & Percent & Cumulative Percent \\
\hline Government officer & 19 & 38.0 & 38.0 \\
\hline Free job & 17 & 34.0 & 72.0 \\
\hline Retired & 4 & 8.0 & 80.0 \\
\hline Housewife & 6 & 12.0 & 92.0 \\
\hline Unemployed & 4 & 8.0 & 100.0 \\
\hline Total & 50 & 100.0 & \\
\hline Monthly income & Frequency & Percent & Cumulative Percent \\
\hline Sufficient & 19 & 38.0 & 38.0 \\
\hline
\end{tabular}




\begin{tabular}{|l|c|c|c|}
\hline Barely sufficient & 21 & 42.0 & 80.0 \\
\hline Insufficient & 10 & 20.0 & 100.0 \\
\hline Total & 50 & 100.0 & \\
\hline Residence & Frequency & Percent & Cumulative Percent \\
\hline Rural & 40 & 80.0 & 80.0 \\
\hline Urban & 10 & 20.0 & 100.0 \\
\hline Total & 50 & 100.0 & \\
\hline
\end{tabular}

Table (2): Mean of score (M.S) for the items of the physical problems

\begin{tabular}{|l|l|c|c|c|c|c|}
\hline No & Items & Always & Some times & Never & M.S & Severity \\
\hline 1 & Cough (productive, nonproductive) & 40 & 5 & 5 & 2.70 & $\mathrm{H}$ \\
\hline 2 & Wheezing & 36 & 9 & 5 & 2.62 & $\mathrm{H}$ \\
\hline 3 & Tight feeling in the chest & 37 & 8 & 5 & 2.64 & $\mathrm{H}$ \\
\hline 4 & Shortness of breathing (orthopnea, excertional dyspnea, & 37 & 8 & 5 & 2.64 & $\mathrm{H}$ \\
\hline 5 & $\begin{array}{l}\text { Dyspnea } \\
\text { paraxymal nocturnal dyspnea) }\end{array}$ & 13 & 5 & 2.76 & $\mathrm{H}$ \\
\hline 6 & Weakness & 42 & 4 & 4 & 2.76 & $\mathrm{H}$ \\
\hline 7 & Fatigue & 42 & 4 & 4 & 2.76 & $\mathrm{H}$ \\
\hline 8 & Trouble sitting still & 5 & 40 & 5 & 2.00 & $\mathrm{M}$ \\
\hline 9 & Cranking worried or scared & 5 & 40 & 5 & 2.00 & $\mathrm{M}$ \\
\hline 10 & Pale & 35 & 11 & 4 & 2.62 & $\mathrm{H}$ \\
\hline 11 & Perspiration & 25 & 16 & 9 & 2.32 & $\mathrm{M}$ \\
\hline 12 & Tachypnea & 10 & 24 & 16 & 1.88 & $\mathrm{M}$ \\
\hline 13 & Shallow breathing & 16 & 29 & 5 & 2.22 & $\mathrm{M}$ \\
\hline 14 & Deep breathing & 24 & 21 & 5 & 2.38 & $\mathrm{M}$ \\
\hline 15 & Tachycardia & 39 & 5 & 6 & 2.66 & $\mathrm{H}$ \\
\hline 16 & Cyanosis & 14 & 5 & 31 & 1.66 & $\mathrm{M}$ \\
\hline 17 & Clubbing of the nail & 11 & 5 & 34 & 1.54 & $\mathrm{H}$ \\
\hline 18 & Loss of the weight & 41 & 4 & 5 & 2.72 & $\mathrm{H}$ \\
\hline 19 & Anorexia & 40 & 5 & 5 & 2.70 & $\mathrm{H}$ \\
\hline 20 & Muscle waste & 19 & 4 & 27 & 1.84 & $\mathrm{M}$ \\
\hline 21 & Anemia & 36 & 5 & 9 & 2.54 & $\mathrm{H}$ \\
\hline & Total & & & & 2.37 & $\mathrm{M}$ \\
\hline
\end{tabular}

Table (3): Correlation coefficient between (age, gender, marital status, educational level, occupation, monthly income, and residence) with physical problems

\begin{tabular}{|l|l|l|l|l|l|l|l|l|}
\hline Correlation & Age & Gender & Marital & Education & Occupation & Monthly & Residence & physical \\
\hline Age & $\mathbf{1}$ & - & - & - & - & - & - & - \\
\hline Gender & .155 & $\mathbf{1}$ & - & - & - & - & - & - \\
\hline Marital status & $-.415^{* *}$ & $-.389^{* *}$ & $\mathbf{1}$ & - & - & - & - & \\
\hline Educational level & -.017 & $-.292^{*}$ & $.614^{* *}$ & $\mathbf{1}$ & - & - & - & - \\
\hline Occupation & .138 & $.324^{*}$ & -.099 & .156 & $\mathbf{1}$ & - & - & - \\
\hline Monthly income & $-.634^{* *}$ & -.209 & $.754^{* *}$ & $.639^{* *}$ & $-.282^{*}$ & $\mathbf{1}$ & - & - \\
\hline Residence & $-.653^{* *}$ & $-.312^{*}$ & .245 & .164 & -.277 & $.459^{* *}$ & $\mathbf{1}$ & - \\
\hline Physical problems & .162 & -.211 & .068 & -.006 & .127 & -.196 & -.152 & $\mathbf{1}$ \\
\hline
\end{tabular}




\section{DISCUSSION}

The results of study samples indicated that the majority (46\%) of the age groups were (40-49) years old. Most of the study samples $(72 \%)$ were male. Most of them (72\%) were married. The majority of the study samples $(46 \%)$ was read and writes. Most of the study samples (38\%) were government officer and most of them (42\%) were barely sufficient. The majority of study samples $(80 \%)$ were from rural area.

Another study reported that the prevalence of asthma in 18-44years of age. Asthma affects an estimated 20 million Americans among adults women have a $30 \%$ greater prevalence of asthma than men that disagree with the results of the study may be because the different in causes of asthma such as smoking as example. The ethnic health disparities are likely due to the low income levels of these populations, the inability to access medical care, and inability to afford the primary treatment for asthma. An increase in allergens in the environment, especially in the inner city (Smeltzer et al., 2010; Anderson, 2007).

The findings of the study samples shows that the mean of score are high level on items $\{1$ [Cough (productive, nonproductive)], 2, Wheezing 3 Tight feeling in the chest, 4 Shortness of breathing, 5 Dyspnea (orthopnea, excertional dyspnea, paraxymal nocturnal dyspnea), 6 Weakness, 7 Fatigue, 10 Pale, 15 Tachycardia, 17 Clubbing of the nail, 18 Loss of the weight, 19 Anorexia and 21 Anemia).The mean of score are moderate on the remaining items.

Most of the study indicated that the characteristic clinical of asthma are wheezing, cough, dyspnea, and chest tightness after exposure to a precipitating factor or trigger (Smeltzer et al., 2010 ; WHO, 2009).

The findings of the study samples shows that there is strong positive relationship between marital status with [educational level $\left(\mathrm{r}=.614^{* *}\right.$, monthly income $\left.\left(\mathrm{r}=754^{* *}\right)\right]$ and strong positive relationship between level of education with monthly income $\left(\mathrm{r}=.639^{* *}\right)$. The table also shows there is strong negative relationship between age with [monthly income $\left(\mathrm{r}=-.634^{* *}\right)$, residence $(\mathrm{r}=$ $\left..653^{* *}\right)$, There is no relationship between physical problems with [marital status ( $\mathrm{r}=.068)$, educational level $(\mathrm{r}=-.006)]$.There is moderate relationship between the remaining variables this mean that physical problems is present with all variables.

Another study indicated that asthma is a severe public health problem that affects a significant portion of the population. Three major physical characteristics are associated with asthma, and people with the disease can manifest one, two or all three of them (wheezing, coughing, chest tightness, and shortness of breath) (Jenkins et al., 2004). Most of other study reported that asthma affects people of all ages (Smeltzer et al., 2008; Basavanthappa, 2009; Lewis et al., 2004; Burrows et al., 1989).

\section{CONCLUSIONS}

Based on the results of the study, the researcher concluded that the majority of the age of the patients were (40-46) year and most of the patients were male and living in rural areas. In addition, it concluded that most of the patients with asthma were married and most of the patients were read and write graduate only. The majority of the patients were government officers with barely sufficient monthly income. Furthermore, most of the patients with asthma have high physical problems such as (Cough (productive, nonproductive, Wheezing, Tight feeling in the chest, Shortness of breathing, Dyspnea (orthopnea, excertional dyspnea, paraxymal nocturnal dyspnea), Weakness, Fatigue, Pale, Tachycardia, Clubbing of the nail, Loss of the weight, Anorexia and Anemia), and moderate on the remaining items. Finally, the findings of the study samples shows that there is strong positive relationship between marital status with [educational level and monthly income and strong positive relationship between level of education with monthly income. The table also shows there is strong negative relationship between age with [monthly income, and residence.

\section{RECOMMENDATION}

Based on the conclusions, the study recommended that efforts should be made to organize specialized teams of health care professionals trained to administer to patients an integrated course combining therapy with the necessary information to help them cope better. In addition, Patients with asthma should undergo tests to identify the substances that precipitate the physical problems. Furthermore, Patients are instructed to avoid the causative agents wherever possible. In addition, a study can be conducted to investigate the physical problems of the patients and employee who have asthma, to develop information and counseling. Knowledge is the key to quality asthma care, Self-care special program upon patients with asthma. The study also concluded that heath education should be given to patient and his family about detecting signs and symptoms for asthma. Carrying out other studies to evaluate the patients with asthma on their quality of life. Providing centers for asthma under treatment for giving various services to help 
patients with good life in home and community. Finally, the study recommended to carrying out nursing care programmed on patients with asthma during treatment and establish strategies for identifying and treating patients within a context of comprehensive follow- up care, including prior emotional adjustment the presence of environmental support and the offer of planned counseling.

\section{REFERENCES}

Anderson, HR., Gupta, R., Strachan, DP. (2007). 50 years of asthma: UK trends from 1955 to 2004. Thorax J. 62 (1). pp.85-90.

Basavanthappa, B. (2009). Medical-Surgical Nursing. $\left(2^{\text {nd }}\right.$ ed.). Jaypee Brothers medical publishers, NewDelhi. P.337.

Beuther, DA. (2010). Recent insight into obesity and asthma. Curr Opin Pulm Med J. 16 (1). pp. 64-70

Boulet, LP. (2009). Influence of comorbid conditions on asthma. Eur Respir J. 33 (4). pp. 897-906.

Burrows, B., Martinez, FD., and Holonen M. (1989). Association of asthma with serum $\mathrm{IgE}$ levels and skin-test reactivity to allergens. $N$ Engl J Med. 320 (5). pp. 271277.

Celedon, JC., Litonjua, AA., Ryan, L.(2002). Exposure to cat allergen, maternal history of asthma, and wheezing in first 5 years of life. Lancet J. 360 (9335). pp. 781-782.

Delacourt, C. (2004). Bronchial changes in untreated asthma. Archives de Pédiatrie $J$. 11 (2). pp. 71s-73s.

Harrington, JJ., and Lee-Chiong, T. (2007). Sleep and older patients. Clin Chest Med J. 28 (4). p 673-84

Holguin, F., and Fitzpatrick, A. (2010). Obesity, asthma, and oxidative stress. J. Appl. Physiol. 108 (3. pp. 754-759.

Jenkins, C., Costello, J., and Hodge, L. (2004). Systematic review of prevalence of aspirin induced asthma and its implications for clinical practice. BMJ. 328 (7437). p. 434.

Lewis, Sh., Heitkemper, M., and Dirksen, Sh. (2007). Medical-Surgical Nursing. ( $2^{\text {nd }}$ ed.). Mosby, Philadelphia, USA. Pp. 608- 629.

Lewis, Sh., Heitkemper, M., Dirksen, Sh. (2004). Medical-Surgical Nursing. ( $2^{\text {nd }}$ ed.). Mosby, Philadelphia, USA. pp. 247-24
Linton, A. (2007). Introduction to MedicalSurgical Nursing. $\left(4^{\text {th }}\right.$ ed.). Saundders Co. Singapore. PP.550-553.

Maddox, L., and Schwartz, DA. (2002). The pathophysiology of asthma. Annu. Rev. Med.J. 53(1). pp.477-498.

Moore, WC., and Pascual, RM. (2010). Update in asthma 2009. American Journal of Respiratory and Critical Care Medicine. 181 (11). pp. 1181-1187.

Nemery, B., Hoet, PH., and Nowak, D.(2002). Indoor swimming pools, water chlorination and respiratory health. Eur. Respir. J. 19 (5). pp 790-793.

Pasternack, R., Huhtala, H., and Karjalainen, J. (2005). Chlamydophila (Chlamydia) pneumoniae serology and asthma in adults: a longitudinal analysis. J. Allergy Clin. Immunol. 116 (5). pp.1123-1128.

Self, T., Chrisman, C. and Finch, Ch. (2009). Applied Therapeutics: The Clinical Use of Drugs. ( $9^{\text {th }}$ ed.). Lippincott Williams and Wilkins, Philadelphia, USA. pp. 453-457.

Simpson, BM., Custovic, A., Simpson, A. (2001). NAC Manchester Asthma and Allergy Study (NACMAAS) "Risk factors for asthma and allergic disorders in adults". Clin Exp Allergy J. 31 (3). pp. 391-399.

Smeltzer, S., Bare, B., Hinkle, J. and Cheever, K. (2010). Textbook of Medical-Surgical Nursing.(12 ${ }^{\text {th }}$ ed.). Philadelphia; LippincottWilliams and Wilkins, USA. pp.620-630.

Smeltzer,S., Bare, B., Hinkle, J., and Cheever, K. (2008). Textbook of Medical-Surgical Nursing. (11 $1^{\text {th }}$ ed.). Philadelphia, LippincottWilliams and Wilkins, USA. pp.709-718.

World Health Organization (WHO). (2009). Fact Sheet Fact sheet No 307: Asthma. Retrieved from:

http://www.who.int/mediacentre/factsheets/f s307/en/print.html on January 2012

World Health Organization (WHO). Report (2009). Retrieved from: http://www.who. int/healthinfo/global burden disease/estimat es country/en/index.html on January 2012.

Zuskin, E., Lipozenci, J., and Pucarin-Cvetkovi. J. (2008). Ancient medicine--a review. Acta Dermatovenerologica Croatica J. 16 (3). P.p 149-57. 